\title{
Testing the validity of ICD-11 PTSD and CPTSD among refugees in treatment using latent class analysis
}

\author{
Maria Louison Vang*, Sabrina Brødsgaard Nielsen**, Mikkel Auning- \\ Hansen***, Ask Elklit***
}

\section{Key points of interest}

- The ICD-11 proposal for PTSD and CPTSD is supported in a culturally heterogenous sample referred for treatment at a Danish facility.

- The majority of referrals qualified for a diagnosis of CPTSD, suggesting that more comprehensive treatment paradigms than those offered for PTSD alone is required for this population.

\begin{abstract}
Introduction: The WHO has proposed posttraumatic stress (PTSD) and Complex PTSD (CPTSD) as trauma-related 'sibling' disorders in ICD-11. The proposal has
\end{abstract}

*) Ulster University, School of Psychology and Psychology Research Institute and National Centre for Psychotraumatology, University of Southern Denmark, Odense, Denmark

Correspondence to: m.vang@ulster.ac.uk

$\star \star)$ Rehabilitation Center for Torture Survivors (RCT-Jutland), Haderslev, Denmark

Correspondence to: sabrinafjorgensen@hotmail.com

$\star \star \star)$ Rehabilitation Center for Torture Survivors (RCT-Jutland), Haderslev, Denmark

Correspondence to: auning@gmail.com

$\star \star \star \star)$ National Centre for Psychotraumatology,

University of Southern Denmark, Odense, Denmark

Correspondence to: aelklit@health.sdu.dk received support from research among clinical and community samples alike but only a few studies have tested the validity of these disorders in a sample of refugees using the International Trauma Questionnaire especially designed for assessment of ICD11 PTSD and CPTSD.

Methods: Latent class analysis was used to test the validity of the ICD-11 PTSD and CPTSD distinction in a heterogeneous group of 284 highly symptomatic refugees registered for treatment at a Danish treatment center.

Results: A two-class solution fit the data best. One group reported elevated levels of PTSD-symptoms and symptoms of affective dysregulation, and one group reported elevated levels of symptoms corresponding to CPTSD. The CPTSD group was considerably larger than the PTSD-group.

Discussion: The current study supports the ICD-11 distinction between PTSD and CPTSD in a sample of treatmentseeking refugees. The assistance of interpreters was needed for some of the participants which affected the reliability of the assessment.

Conclusion: The ICD-11 proposal for PTSD and CPTSD is supported in a heterogenous sample of refugees using the ITQ.

Keywords: PTSD, Complex PTSD, refugee, ICD-11, International Trauma Questionnaire 


\section{Introduction}

The United Nations High Commissioner for Refugees (UNHCR) estimates that every two seconds, a person is displaced due to armed conflict or persecution, making the current estimate of 68.5 million forcibly displaced people at the end of 2017 the largest number of refugees the world has ever witnessed (UNHCR, 2018). Out of these, an estimated 25.4 million people were refugees and 3.1 million were asylum seekers, meaning that over $1 / 3$ of displaced people worldwide have fled their home-country due to human rights violations. In 2018, a total of 3.120 asylumseekers arrived in Denmark, bringing the number of forcibly displaced persons hosted in Denmark specifically up to 47.927 people (UNHCR, 2018).

While estimates vary, between $30 \%$ and $44 \%$ of refugees are presumed to be survivors of torture (DIGNITY, 2019; US Dept. of Health and Human Service, 2019), and research has established that refugees report a broad history of exposure to potentially traumatizing events (Tay, Rees, Tam, Kareth \& Silove, 2018) as well as high rates of common mental health problems such as anxiety, depression and posttraumatic stress disorder (PTSD, Bogic, Njoku \& Priebe, 2015; Fazel, Wheeler \& Danesh, 2005; Silove et al., 2018).

Consequently, a systematic review estimated that refugees could be up to 10 times more likely to qualify for a diagnosis of PTSD than age-matched comparison groups of the general population (Fazel, Wheeler \& Danesh, 2005), and only experience moderate recovery from mental health difficulties during the first decade after immigrating (Tam, Houlihan \& MelendezTorres, 2015). In conjunction with findings from Denmark suggesting that refugees have spent an average of 14 years in the country before accessing specialized mental health care services (Competence Centre for Transcultural Psychiatry, 2015), the provision of adequate and timely mental health care to forcibly displaced persons is a pivotal concern to be addressed in countries hosting and rehabilitating asylum seekers and refugees.

For the 11 th revision of the International Classification of Diseases (ICD-11), the World Health Organization (WHO) has proposed two sibling disorders; PTSD and complex PTSD (CPTSD) (Maercker et al., 2013a; Maercker et al., 2013b) to enhance the cross-cultural validity and clinical utility of diagnoses following exposure to extreme stress. PTSD is comprised of three symptom clusters designed to capture the core elements of posttraumatic stress responses: re-experiencing in the here-andnow; avoidance of internal and external reminders of a traumatic experience; and a sense of hypervigilance. Each symptomcluster consists of two symptoms, thereby representing a considerable downsizing of the diagnostic criteria compared to previous and current conceptualizations of PTSD (APA, 2008; 2013). CPTSD is composed of the PTSD diagnosis and three additional symptom-clusters representing disturbances in self-organization (DSO): affective dysregulation, negative selfconcept, and disturbances in interpersonal relationships (Maercker et al., 2013a; Maercker et al., 2013b). This thereby encompasses broader and more pervasive posttraumatic symptomatology that was previously described under the DSM-IV diagnosis 'Disorder of Extreme Stress Not Otherwise Specified (DESNOS)' and frequently diagnosed in refugees (Palic, 2013). Currently, several studies support the proposed ICD-11 PTSD and CPTSD factors structure in clinical and community populations alike (Brewin et al., 2017) 
Research has shown that CPTSD is more commonly reported than PTSD following prolonged exposure to multiple severe traumatic experiences from which escape is difficult or impossible (Brewin et al., 2017; Hyland et al., 2017b; Maercker et al., 2013a). Hence, CPTSD might be particularly relevant when describing posttraumatic responses among refugees exposed to organized violence, war and persecution (Murphy, Dokkedahl, Elklit \& Shevlin, 2016). Some studies have examined CPTSD in refugee samples, yielding prevalence rates of PTSD ranging from $20 \%$ to $32.9 \%$ and prevalence rates of CPTSD ranging from $21 \%$ to $50.9 \%$ (Grossman et al., 2019; Hecker, Huber, Maier \& Maercker, 2018; Hoffman et al., 2018; Nickerson, Cloitre, Bryant, Schnyder, Morina, \& Schick, 2016; Shevlin et al., 2018). Additionally, most studies conducted on the validity of ICD-11 PTSD and CPTSD have provided preliminary evidence for the validity of the CPTSD construct within samples of treatment-seeking refugees (Nickerson et al., 2016; Palic, Zerach, Shevlin, Zeligman, Elklit, \& Solomon, 2016) and resident refugees (Frost, Hyland, McCarty, Halpin, Shevlin \& Murphy, 2018; Tay, Moshin, Rees, Tam, Kareth \& Silove, 2018), whereas one study of resident refugees found that the factor structure of ICD-11 PTSD fit the data well, while the CPTSD factor structure did not (Tay, Rees, Chen, Kareth, and Silove 2015). The findings cited above were however limited in examining CPTSD in refugees due to the reliance on measures not specifically designed to measure the ICD-11 diagnoses of PTSD and CPTSD.

Recently however, the International Trauma Questionnaire (ITQ), a self-report questionnaire used to measure the ICD11 diagnoses of PTSD and CPTSD, was developed and validated with the specific purpose of identifying and distinguishing ICD-11 PTSD and CPTSD (Cloitre, Roberts, Bisson, \& Brewin, 2013; Cloitre et al., 2018). The ITQ has shown satisfactory reliability across international community and clinical trauma-exposed populations alike (Karatzias et al., 2017), and recently, two studies have examined the validity of ICD-11 PTSD and CPTSD in a sample of treatment-seeking refugees. Valliéres et al. (2018) found support for a two-factor higher order model consistent with the ICD-11 proposal using confirmatory factor analysis in a homogenous sample of Syrian refugees resettled in Lebanon. Likewise, Hyland et al. (2018) replicated evidence reported across different countries for individual symptom profiles consistent with the ICD-11 proposal for PTSD and CPTSD (Murphy et al., 2016) using latent class analysis in Syrian refugees resettled in Lebanon.

Currently, Hyland et al. (2018) and Valliéres et al. (2018) appear to be the only published studies using the ITQ to investigate the validity of the ICD-11 proposal for PTSD and CPTSD among refugee populations. This thereby contributes to extending existing evidence for the cross-cultural validity of the constructs in culturally homogenous samples. Clinics offering mental health care to refugees are however often faced with culturally diverse samples of care recipients, and while a recently published study used the ITQ to identify specific predictors of ICD-11 PTSD and CPTSD among a culturally diverse sample of refugees in Switzerland (Hecker et al., 2018), it appears that no published studies has yet tested the validity of ICD11 PTSD and CPTSD using the ITQ in a culturally heterogenous sample of treatmentseeking refugees. 


\section{Study aim}

The purpose of the present study is to examine the distribution of ICD-11 PTSD and CPTSD symptoms among a culturally heterogenous sample of treatment-seeking refugees by using latent class analysis (LCA) and the ITQ. Based on existing evidence, we hypothesized that the LCA would identify classes corresponding to the diagnostic criteria of ICD-11 PTSD and CPTSD. A secondary purpose of the study is to explore the relationship between classmembership and demographic and traumarelated variables.

\section{Methods}

\section{Participants and procedure}

The current study is based on a consecutive sample of patients referred to Rehabilitation Center for Torture Survivors - Jutland (RCTJutland), a specialized treatment center in Denmark. The RCT-Jutland provides treatment to refugees who have been exposed to organized violence or assaults (such as war, torture and persecution) in another country. Conditions for being offered treatment and concurrently inclusion criteria for the current study were: having obtained legal residence in Denmark; and a referral from a general practitioner or psychiatrist for assessment and treatment for traumarelated mental health problems. Exclusion criteria were the absence of Danish healthcare insurance or legal permission to stay in Denmark; and the presence of a primary psychotic disorder requiring psychiatric treatment. Upon referral, patients are enrolled in an assessment program that includes standardized measures at baseline (intake), end of treatment, and at 9 months follow up. The ITQ was implemented in the assessment program from December 2015 onwards, and the participants for the current study was composed of patients referred for treatment between December 2015 and April 2018 who were asked to complete the ITQ at enrollment. Hence, baseline data from the assessment formed the data for the current analysis using the ITQ-assessment from a total sample of 284 patients. Interpreters were provided according to language and needs: Assistance from an interpreter was required for $69.9 \%(n=197)$ of the participants. The mean age of the participants was 40.94 years $(\mathrm{SD}=9.77$, range $=17-68$ years $)$, and $52.5 \%$ of the participants were men $(\mathrm{n}=149)$. A total of 24 nationalities were represented in the sample across 6 different regions: The Middle East $(\mathrm{n}=177)$, South-Eastern Europe $(n=80)$, Caucasus $(n=8)$, Asia $(n=7)$, Africa $(n=7)$, and Northern Europe $(n=2)$. The most frequently represented countries were Syria (Middle East, $n=122$ ), Bosnia (South-Eastern Europe, $n=50$ ), Afghanistan (Middle East, $\mathrm{n}=25$ ) and Kosovo (SouthEastern Europe, $n=21$ ).

Respondents came to Denmark in the years from 1986 to 2017 . The median year of arrival was 2011, and data on year of arrival was missing for $n=20$ participants. Most respondents were married or living in a registered partnership $(73 \%, \mathrm{n}=205)$, had one or more children under the age of $18(77.9 \%, \mathrm{n}=208)$, did not have Danish citizenship (86.1\%, $\mathrm{n}=242)$ and had never worked in Denmark $(47.3 \%, \mathrm{n}=134)$. $8.8 \%$ of participants did not provide any information on employment. The study was conducted in accordance with the Helsinki Declaration and was approved by the Danish Data Protection Agency. Written informed consent was obtained from all participants.

\section{Measures}

Demographic information: Basic demographic information was gathered using questions selected specifically for the 
assessment at RCT-Jutland. The available information for the current study included: gender of the participant (male/female), age in years, year of arrival in Denmark, country of origin, marital status, parental status (children under age of $18 /$ no children), citizenship status (Danish/nonDanish) and occupational status (having ever worked in Denmark).

ICD-11 PTSD and CPTSD: The International Trauma Questionnaire (ITQ; Cloitre, Roberts, Bisson, \& Brewin, 2013; Cloitre et al., 2018). It includes one item per symptom of PTSD and CPTSD as displayed in table 3. CPTSD is comprised of PTSD and DSO. All items are rated using self-report on a 5-point Likert scale $(0=$ 'not at all', $4=$ 'extremely' $)$, and an item was considered endorsed if the patient indicated a score $\geq 2$ ('moderately'). The ITQ also includes an open-ended question assessing the index trauma and time since the index-trauma. Only the subjectively rated most severe trauma was reported for each participant. The ICD-11 Trauma Questionnaire was translated into Danish by Ask Elklit (2015) and into Bosnian and Arabic using a back-translation procedure with trained and experienced interpreters and clinicians. If the participant was not able to read Danish, Bosnian or Arabic during the assessment, a trained clinician would read the items aloud and the interpreter would translate the questions and answers, after which the clinician would record the answers. Likewise, the questionnaire was read aloud to participants who were illiterate. The ITQ was completed as self-report by $29.4 \%(n=80)$ of the participants and read aloud to $70.6 \%(\mathrm{n}=$ 192) of the participants.

The psychometric properties of the ITQ have previously been validated in clinical and community samples alike (Ben-Ezra et al.,
2018; Hyland, Shevlin, Fyvie \& Karatzias, 2018; Karatzias et al., 2017; Murphy et al., 2016). The internal reliability as measured by Cronbach's $\alpha$ was acceptable in the current sample: PTSD: .74; Re-experiencing: 0.70; Avoidance: .62; Hypervigilance: .55; DSO: .83; Affective dysregulation: .53; Negative self-concept: .82; Disturbed relationships: .73 , CPTSD (full scale): .84. As the reliability coefficients for hypervigilance and affective dysregulation were slightly lower than desired (for an overview of studies investigating the ICD-11 conceptualizations, see Brewin et al., 2017), reliability for these scales was investigated separately for participants receiving assistance from an interpreter in completing the questionnaire.

\section{Statistical analysis}

The analysis was conducted in two linked phases: First, item endorsement for each of the PTSD and DSO-domains was computed using the cut-off-value $\geq 2$ (Karatzias et al., 2017). A latent class analysis (LCA) was conducted to test whether patterns of item endorsement corresponding to the diagnoses of PTSD and CPTSD could be identified in the sample. LCA is a statistical method used to assess the presence of unobservable homogenous groups in the data based on item-response patterns. It is particularly well-suited for identification of latent psychological constructs such as psychological traumatization that is unobservable per se, but the presence of which may be detectible through observable data related to the construct (Murphy, Houston \& Shevlin, 2007). LCA assumes that the associations between observed data points can be explained by a finite number of unobservable homogenous groups of individuals that are mutually exclusive (Debowska, Willmott, Boduszek \& Jones, 2017). These are referred to as 
latent classes. In this case, the presence of psychological traumatization is inferred by the endorsement of two specific patterns of co-occurring symptoms consistent with PTSD and CPTSD. Two steps are involved in conducting LCA. Firstly, unobserved relationships between the patterns of endorsement of symptoms of posttraumatic stress is identified by exploring the relative fit of a range of models describing unobserved groups in the data. As per the recommendations of Debowska et al. (2017), we tested the fit of a 1- through 6 -class model. The relative fit of the models is decided based on a range of fit indices described below. Upon identification of the best fitting model, LCA assigns each participant to one of the latent classes on a probabilistic basis depending on the match between the individual response pattern and the latent classes' response patterns. As this classification is probabilistic in nature, model entropy is estimated as a standardized index reflecting the classification accuracy of individuals under the different models. All models are estimated using robust maximum likelihood (Yuan \& Bentler, 2000) and to avoid solutions based on local maxima, 500 random sets of starting values were used with 100 final stage optimizations. The relative fit of the models was compared using the following parsimonious fit statistics: the Akaike Information Criterion (AIC; Akaike, 1987), the Bayesian Information Criterion (BIC; Schwarz, 1978), and sample size adjusted Bayesian Information Criterion (ssaBIC; Sclove, 1987). These estimates can be used to compare competing statistical models of the latent structure of the same data to the observed sample distribution in the data. Lower values indicate better fit of the statistical model to the observed data. The Lo-Mendell-Rubin adjusted likelihood ratio (LMR-A; Lo, Mendell, \& Rubin,
2001) and bootstrapped likelihood ratiotest (BSLRT, McLachlan \& Peel, 2000) was used to assess whether models with additional classes constituted a statistically significant improvement in describing the data compared to the previous models. When a non-significant value $(\mathrm{p}>0.05)$ occurs, this suggests that the model does not provide a statistically significantly better description of the data compared to the previous model. Finally, the entropy of each solution was assessed to evaluate the accuracy of the classification of individuals. Entropy is reported on a standardized scale with values that are closer to 1 indicative of better classification (Ramaswamy, DeSarbo, Reibstein, \& Robinson, 1993). A Chi-square $\left(\chi^{2}\right)$-test was used to validate the best fitting class solution with probable diagnosis computed according to the ICD-11 criteria ${ }^{1}$.

Finally, the relationship between class-membership and 8 covariates were tested by means of the R3STEP auxiliary variable approach in Mplus (Asparouhov \& Muthén, 2014). This approach estimates the relationship between predictors and classmembership while taking into account the imperfection of classification of individuals as indicated by the entropy values. The R3STEP procedure is analogous to a logistic regression using latent class-membership as dependent variables and covariates as independent variables. Covariates included age, gender, citizenship-status, type of index-trauma, marital status, occupational status, need for interpreter, time since trauma and region of origin. Categorical variables with more than two categories (region and time since trauma) were dummy

1 Readers looking for a more comprehensive introduction to LCA are referred to Murphy, Houston and Shevlin (2007). 
coded before the analysis. There were no missing data on the PTSD items, and four participants had missing data on the DSO items corresponding to $1.4 \%$ (AD and DR). Missing data was handled using maximum likelihood estimation in step 1 of the analysis. There were between $0 \%$ (age, gender) and $10 \%$ (occupational status) missing data for the correlates. Missing data was handled using listwise deletion in step 2 of the analysis. All analyses were conducted using two-sided hypothesis testing with a p-level of $<.05$. All analyses were conducted using Mplus version 8.1 (Muthén \& Muthén, 2018) and SPSS version 25.

\section{Results}

Table 1 presents the results from separate Cronbach's alpha analyses for respondents requiring the assistance of an interpreter versus the respondents comfortable filling in the questionnaire on their own.

Table 1: Reliability estimates of ITQ hypervigilance and affective dysregulation subscales.

\begin{tabular}{lll}
\hline & Hypervigilance & Affective dysregulation \\
\hline No interpreter & $\alpha=.61(\mathrm{n}=81)$ & $\alpha=.61(\mathrm{n}=82)$ \\
Interpreter & $\alpha=.53(\mathrm{n}=195)$ & $\alpha=.48(\mathrm{n}=191)$ \\
All participants & $\alpha=.55(\mathrm{n}=278)$ & $\alpha=.53(\mathrm{n}=275)$ \\
Inter-item correlation, & $\mathrm{r}=.38$ & $\mathrm{r}=.36$ \\
All participants & &
\end{tabular}

Note: $\alpha=$ Cronbach's alpha. $r=$ Pearson's $r$.

The frequencies of index trauma-types are presented in Table 2. Male participants were significantly more likely to report torture or imprisonment as index trauma, whereas female participants were more likely to report having experienced war as index trauma. The ITQ-item endorsementrates are presented in Table 3. Notably, both symptom endorsement and symptom severity were high with each item endorsed by a majority of the participants, and the average symptom score ranging from 2.46 ("moderately" - "quite a bit") to 3.31 ("quite a bit" - "extremely"). There were no statistically significant gender differences in endorsement of symptom clusters.

Table 4 displays the LCA fit statistics. The best log-likelihood value was not replicated for classes five and six even after increasing the number of random starts to
5000 and final stage optimizations to 1000 , suggesting that the models might be misspecified for the current data (Geiser, Eid, Nussbeck, Courvoisier \& Cole, 2010). Of the remaining models, the 2- and 3-class models displayed the lowest AIC, BIC, ssaBIC and log-likelihood values, and both represented a statistically significant contribution over their predecessor as per the LRM-A and BSLRTvalues. The 3-class model had higher entropyvalues, suggesting better classification of cases than the 2-class model, whereas the 2-class model displayed a 9 point lower BIC-value, bordering on the suggested cut-off for "very strong" evidence in support of the model with the lowest value (10 points, Raftery, 1995). Upon inspection of the 2- and 3-class solutions, it was evident that both models identified a class characterized by elevated risk of all symptoms (a CPTSD-class), and 
Table 2: Frequency of index trauma-types in sample.

\begin{tabular}{lllll}
\hline Trauma-type & Total \%(284) & Male \%(149) & Female \%(135) & $\chi^{2}, \mathrm{p}$ \\
\hline War $^{\star}$ & $81.7 \%(232)$ & $78.6 \%(114)$ & $90.1 \%(118)$ & $6.74, .01$ \\
Torture $^{\star}$ & $7.4 \%(21)$ & $13.1 \%(19)$ & $2.3 \%(3)$ & $10.97, .001$ \\
Violence & $3.5 \%(10)$ & $2.1 \%(3)$ & $5.3 \%(7)$ & $2.11, .15$ \\
Witnessing death & $7.4 \%(21)$ & $6.9 \%(10)$ & $8.4 \%(11)$ & $0.22, .64$ \\
Imprisonment & $13.4 \%(38)$ & $22.8 \%(33)$ & $3.8 \%(5)$ & $20.8, .001$ \\
Military service & $1.4 \%(4)$ & $2.8 \%(4)$ & $0 \%(0)$ & $3.69, .06$ \\
Fleeing & $6.7 \%(19)$ & $7.6 \%(11)$ & $6.1 \%(8)$ & $0.24, .69$ \\
Death of a close one & $6.7 \%(19)$ & $5.5 \%(8)$ & $8.4 \%(11)$ & $0.89, .35$ \\
Other & $10.9 \%(31)$ & $11.7 \%(17)$ & $10.7 \% 14)$ & $0.07, .79$ \\
\hline
\end{tabular}

Time since trauma

\begin{tabular}{lllll}
\hline Less than 6 months & $1.8 \%(5)$ & - & - & - \\
6-12 months & $1.8 \%(5)$ & - & - & - \\
1-5 years & $34.8 \%(98)$ & $36.2 \%(54)$ & $32.6 \%(44)$ & $0.417, .52$ \\
5-10 years & $12.8 \%(36)$ & $13.4 \%(20)$ & $11.9 \%(16)$ & $0.158, .69$ \\
10-20 years & $17.7 \%(50)$ & $18.8 \%(28)$ & $16.3 \%(22)$ & $0.304, .58$ \\
More than 20 years & $31.2 \%(88)$ & $26.2 \%(39)$ & $55.7 \%(49)$ & $3.393, .06$
\end{tabular}

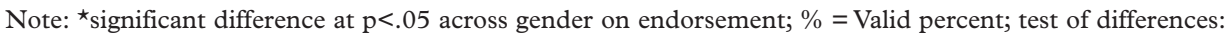
Pearson's $\chi^{2}$ asymptotic sig. (2-sided). Data was missing for 8 respondents.

a class characterized by elevated risk of endorsing symptoms consistent with PTSD and affective dysregulation. The third class identified in the latter model represented 2.9 $\%$ of the sample that presented with elevated risk of endorsing DSO symptoms only. As the 2-class solution (in bold) was deemed the best description of the data based on the BIC value. Nylund et al. (2007) have shown that classes comprising less than $5 \%$ of the sample can cause problems with model convergence and since the BIC includes a penalty for model-complexity and therefore is the preferred information criterion for identifying the best-fitting model (Nylund, Asparouhov, \& Muthen, 2007). Entropyvalues for the 2-class solution remained within an acceptable range and the posterior probabilities ranged from 0.893 to 0.970 (Ramaswamy et al., 1993). The profile plot and probabilities for the two-class solution are shown in Figure 1.

Probability of endorsement indicates the likelihood that participants in the respective class have endorsed the item in question. This probability ranges from 0 to 1 , where 0 equals that participants in the class did not endorse the item, whereas 1 equals 
Table 3: Endorsement of ITQ-items measuring PTSD and DSO.

\begin{tabular}{|c|c|c|c|}
\hline ITQ & & $\%(\mathrm{n})$ & $\begin{array}{l}\text { Mean }(\mathrm{SD}) \\
\text { (range: } 0-4)\end{array}$ \\
\hline \multicolumn{4}{|l|}{ PTSD } \\
\hline \multicolumn{2}{|l|}{ Re-experiencing } & \multicolumn{2}{|l|}{$95.1 \%(270)$} \\
\hline $\operatorname{Re} 1$ & $\begin{array}{l}\text { Upsetting dreams that replay part of the event or } \\
\text { are clearly related to the event? }\end{array}$ & $91.5 \%(260)$ & $3.14(1.1)$ \\
\hline $\operatorname{Re} 2$ & $\begin{array}{l}\text { Powerful images or memories that sometimes } \\
\text { come into your mind in which you feel the event }\end{array}$ & $89.8 \%(255)$ & $3.10(1.14)$ \\
\hline \multicolumn{2}{|l|}{ Avoidance } & \multicolumn{2}{|l|}{$95.4 \%(271)$} \\
\hline Av1 & $\begin{array}{l}\text { Avoiding internal reminders of the stressful event } \\
\text { experience (for example, thoughts, feelings, or } \\
\text { physical sensations)? }\end{array}$ & $91.1 \%(257)$ & $3.18(1.06)$ \\
\hline Av2 & $\begin{array}{l}\text { Avoiding external reminders of the stressful event } \\
\text { experience (for example, people, places, conversa- } \\
\text { tions, objects, activities, or situations)? }\end{array}$ & $88.6 \%(249)$ & $3.07(1.2)$ \\
\hline \multicolumn{2}{|l|}{ Hypervigilance } & \multicolumn{2}{|l|}{$97.2 \%(276)$} \\
\hline $\mathrm{H} 1$ & Being “super-alert," watchful, or on guard? & $88.9 \%(248)$ & $3.12(1.2)$ \\
\hline $\mathrm{H} 2$ & Feeling jumpy or easily startled? & $92.2 \%(261)$ & $3.31(1.04)$ \\
\hline \multicolumn{4}{|l|}{ DSO } \\
\hline \multicolumn{2}{|c|}{ Affective dysregulation } & \multicolumn{2}{|l|}{$93 \%(264)$} \\
\hline Ad1 & $\begin{array}{l}\text { When I am upset, it takes me a long time to calm } \\
\text { down. }\end{array}$ & $87.9 \%(246)$ & $2.89(1.28)$ \\
\hline $\operatorname{Ad} 2$ & I feel numb or emotionally shut down. & $83.6 \%(230)$ & $2.46(1.56)$ \\
\hline \multicolumn{2}{|c|}{ Negative self-concept } & \multicolumn{2}{|l|}{$75.4 \%(214)$} \\
\hline Nsc1 & I feel like a failure. & $71.2 \%(198)$ & $2.77(1.36)$ \\
\hline Nsc2 & I feel worthless. & $69 \%(191)$ & $2.62(1.4)$ \\
\hline \multicolumn{2}{|c|}{ Disturbed relationship } & \multicolumn{2}{|l|}{$87.3(248)$} \\
\hline Dr1 & I feel distant or cut off from people. & $79.1 \%(219)$ & $2.77(1.36)$ \\
\hline Dr2 & I find it hard to stay emotionally close to people. & $80.1 \%(221)$ & $2.62(1.4)$ \\
\hline
\end{tabular}

Note: Valid percentages reported.

that all participants in the class endorsed the item. Class one $(\mathrm{N}=247,87 \%)$ was the largest class and was characterized by high probabilities of endorsing all symptom clusters. This class was labelled "CPTSD". Class two ( $=37,13 \%)$ was characterized by elevated reports of reexperiencing, avoidance, hypervigilance 
Table 4: LCA fit statistics

\begin{tabular}{|c|c|c|c|c|c|c|c|}
\hline Classes & $\mathrm{Chi}^{2}(\mathrm{df}), \mathrm{p}$ & AIC & $\mathrm{BIC}$ & ssaBIC & LMR-A (p) & BSLRT (p) & Entropy \\
\hline 1 & $\begin{array}{l}209.95 \\
(51),>0.01\end{array}$ & 929.52 & 951.42 & 932.39 & - & - & - \\
\hline 2 & $\begin{array}{l}57.42 \\
(48), 0.165\end{array}$ & 840.61 & 888.05 & 846.82 & $\begin{array}{l}100.37 \\
(0.0001)\end{array}$ & $\begin{array}{l}102.91 \\
(0.000)\end{array}$ & 0.82 \\
\hline 3 & $\begin{array}{l}24.67 \\
(42), 0.984\end{array}$ & 824.08 & 897.06 & 833.64 & $\begin{array}{l}29.78 \\
(0.0049)\end{array}$ & $\begin{array}{l}30.53 \\
(0.0000)\end{array}$ & 0.87 \\
\hline 4 & $\begin{array}{l}20.51 \\
(35), 0.976\end{array}$ & 832.39 & 930.91 & 845.29 & $\begin{array}{l}5.55 \\
(0.4309)\end{array}$ & $\begin{array}{l}5.69 \\
(1.0000)\end{array}$ & 0.88 \\
\hline 5 & $\begin{array}{l}13.90 \\
(28), 0.998\end{array}$ & 839.68 & 963.75 & 855.93 & $\begin{array}{l}6.61 \\
(0.0649)\end{array}$ & $\begin{array}{l}6.76 \\
(0.6667)\end{array}$ & 0.90 \\
\hline 6 & $\begin{array}{l}7,90 \\
(21), 0.996\end{array}$ & 848.84 & 998.45 & 868.44 & $\begin{array}{l}4.74 \\
(0.5451)\end{array}$ & $\begin{array}{l}4.86 \\
(0.6667)\end{array}$ & 0.91 \\
\hline
\end{tabular}

Note: Chi2: Pearson Chi-Square Test of Model Fit for the Binary and Ordered Categorical (Ordinal) Outcomes. $d f=$ degrees of freedom. AIC: Akaike Information Criteria, BIC: Bayesian Information Criteria, ssaBIC: Samplesize adjusted Bayesian Information Criteria, $L M R-A$ : Lo-Mendell-Rubin adjusted likelihood ratio test. BSLRT: Bootstrapped adjusted likelihood ratio test.

and affective dysregulation, as well as comparably lower rates of negative selfconcept and disturbed relationships. This class was labelled "PTSD".

Operationalizing the diagnostic criteria for CPTSD and PTSD based on symptom endorsement alone, 190 participants (66.9 $\%, \mathrm{n}=98$ men) met the diagnostic criteria for CPTSD and 71 participants $(25 \%, n$ $=37$ men) met the criteria for PTSD only. Finally, 23 participants $(8.1 \%, \mathrm{n}=14$ men $)$ did not meet the criteria for either diagnosis. Table 5 displays a cross-tabulation of classmembership and probable diagnostic status as per ICD-11.

Significantly more people were correctly rather than erroneously classified in the LCA using probable diagnostic status as a criterion. Standardized residuals can be interpreted in a way similar to odds ratios, however, while odds ratios refer to relative odds compared to overall likelihood of endorsing a category, standardized residuals are normally distributed and interpreted with reference to the standard deviation where values $\geq 1.96$ indicate a statistically significant difference between the expected and actual class-count at $\mathrm{p} \leq .05$. Notably, most disagreements pertained to the class-membership of the 23 people who did not fulfill a diagnosis using the ICD-1 1 established cut-offs. Out of the participants with no diagnosis, 8 persons endorsed subclinical CPTSD (all DSOsymptoms and 2 PTSD symptoms), and 7 persons endorsed subclinical PTSD (2 PTSD symptoms). Out of the participants classified with PTSD, 47 (66.2\%) met the criteria for subclinical CPTSD. Out of the participants with no diagnosis, the majority was categorized as belonging to the PTSD class $(n=15)$, and 8 people belonged to the CPTSD class in the latent class analysis. The latter 8 were identical to the participants endorsing subclinical CPTSD. 
Figure 1: Profile plot and class-probabilities of symptom-endorsement

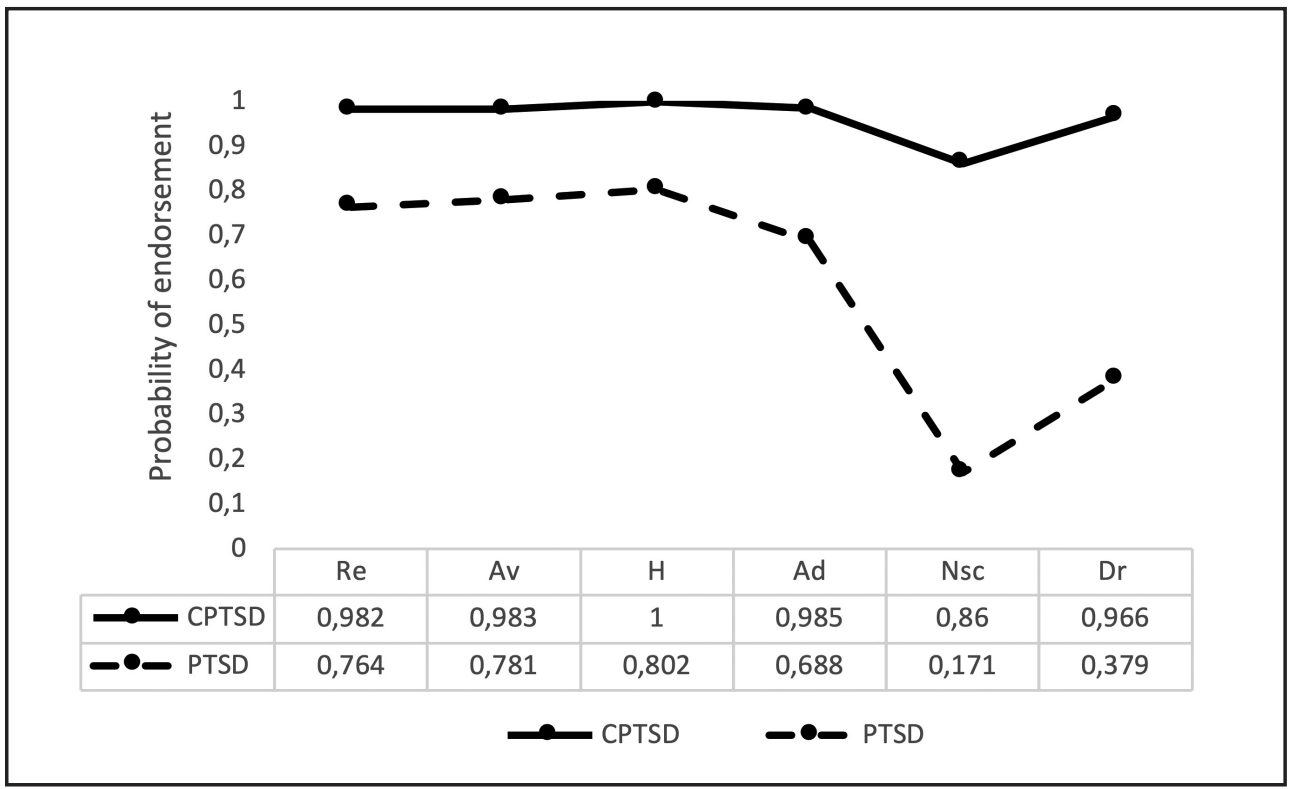

Note: $\mathrm{Re}=\mathrm{Re}$-experiencing, $\mathrm{Av}=$ Avoidance, $\mathrm{H}=$ Hypervigilance, $\mathrm{Ad}=$ Affective dysregulation, Nsc $=$ Negative self-concept, Dr $=$ Dysfunctional relationships.

To address the second aim of the study, table 6 displays the results of the logistic regression-analyses.

No significant differences across classmembership were found.

\section{Discussion}

The purpose of this study was to examine the distribution of ICD-11 PTSD and CPTSD symptoms and explore their relation to sociodemographic and traumarelated variables in a culturally heterogenous group of treatment-seeking refugees by using latent class analysis (LCA). The LCA identified that the participants were distinguishable based on different patterns of symptom endorsement. Consistent with previous research among non-western populations (Hyland et al., 2018; Murphy et al., 2016), a two-class model reflecting the ICD-11 proposal provided the best fit to the data: a CPTSD class characterized by high probabilities of endorsing all PTSD core symptoms and DSO domains, and a PTSD class characterized by elevated PTSD core symptoms and comparably lower rates of DSO domain scores apart from affective dysregulation. Elevated rates of affective dysregulation in addition to PTSD symptoms are consistent with previous studies reporting elevated probabilities of endorsing hyperactivation among the PTSD class in non-western samples (probability $=.64$ in Hyland et al., 2018; .45 Murphy et al., 2016). Overall, the participants in the current study reported high intensity and prevalence of symptoms of PTSD and CPTSD, and affective dysregulation was frequently endorsed with $93 \%$ meeting the cut-off criterion for symptoms of this cluster. 
Table 5: Relationship between class-endorsement and diagnostic status

\begin{tabular}{|c|c|c|c|c|c|c|}
\hline & & & Proba & $\mathrm{D}-11 \mathrm{dic}$ & & Total \\
\hline & & & No diagnosis & PTSD & CPTSD & \\
\hline Class & CPTSD & $\mathrm{n}$ & 8 & 53 & 186 & 247 \\
\hline & & $\%$ within class & $3.2 \%$ & $21.5 \%$ & $75.3 \%$ & $100.0 \%$ \\
\hline & & $\begin{array}{l}\text { Standardized } \\
\text { residual }\end{array}$ & $-2.7^{\star}$ & -1.4 & 1.8 & - \\
\hline & PTSD & $\mathrm{n}$ & 15 & 21 & 1 & 37 \\
\hline & & $\%$ within class & $40.5 \%$ & $56.8 \%$ & $2.7 \%$ & $100.0 \%$ \\
\hline & & $\begin{array}{l}\text { Standardized } \\
\text { residual }\end{array}$ & $6.9^{\star}$ & $3.7^{\star}$ & $-4.7^{\star}$ & . \\
\hline Total & & $\mathrm{n}$ & 23 & 74 & 187 & 284 \\
\hline & & $\%$ within class & $8.1 \%$ & $26.1 \%$ & $65.8 \%$ & $100.0 \%$ \\
\hline
\end{tabular}

Note: Overall $\chi^{2}(2) 96.44, p=.000 .{ }^{\star}$ indicates a statistically significant difference from expected distribution.

A recent study of the structure of ICD-11 PTSD and CPTSD used network-analysis to show that symptoms of hypoactivation and hyperactivation comprising the affective dysregulation domain of DSO was more strongly related to other symptoms of posttraumatic symptomatology than each other (McElroy et al., 2019). In conjunction with documentation for high rates of common mental health disorders among resettled refugees (Turrini, Purgato, Ballette, Nosé, Ostuzzi \& Barbui, 2017), the elevated rates of affective dysregulation among the PTSD class might also be reflective of comorbidity or elevated levels of non-specific distress associated with pre-, peri and postmigration factors. However, more research is needed to explore the relationship between trauma-related factors and specific symptom-clusters of ICD-11 PTSD and CPTSD in refugee samples.

The emergence of a low symptom class has been reported in previous studies using latent class approaches to investigate the validity of ICD-11 PTSD and CPTSD among refugee populations (Frost et al., 2018; Hyland et al., 2018; Murphy et al., 2016). However, the finding of a twoclass model as the best description of the data constitutes a reasonable deviation from existing evidence considering that the current study is based on a treatment-seeking sample with clusterendorsement rates ranging from $75.4 \%$ to $97.2 \%$ reflecting high rates of clinically relevant levels of distress. Indeed, only 23 respondents did not fulfill the criteria for a probable diagnosis of either PTSD or CPTSD, and in the LCA, the CPTSD class was by far the largest. This is consistent with several other studies finding the probable diagnostic rate of CPTSD to be higher than the rate of PTSD in treatmentseeking populations (Cloitre, Garvert, Brewin, Bryant, \& Maercker 2013; Cloitre, Garvert, Weiss, Carlson, \& Bryant, 2014; Hyland et al., 2017b; Hyland et al., 2018; Karatzias et al., 2016, 2017; Knefel \& Lueger-Schuster, 2013; Nickerson et al., 2016), but inconsistent with a recent 
Table 6: Odds ratio for class-membership from logistic regression

\begin{tabular}{|c|c|c|c|}
\hline Correlates & Odds-ratio & $95 \% \mathrm{CI}$ & p-value \\
\hline \multicolumn{4}{|l|}{ Continuous correlates } \\
\hline Age (years) & 0.97 & {$[0.93-1.00]$} & .08 \\
\hline \multicolumn{4}{|l|}{ Categorical correlates } \\
\hline Gender $=$ female & 1.23 & {$[0.44-3.45]$} & .69 \\
\hline Foreign citizenship & 0.38 & {$[0.01-25.57]$} & .65 \\
\hline Marital status & 0.99 & {$[0.12-3.45]$} & .98 \\
\hline $\begin{array}{l}\text { Occupational status (ever } \\
\text { worked in DK) }\end{array}$ & 0.65 & {$[0.12-3.45]$} & .61 \\
\hline $\begin{array}{l}\text { Need for interpreter } \\
(=\text { no })\end{array}$ & 0.4 & {$[0-48.73]$} & .71 \\
\hline Index trauma = war & 0.79 & {$[0.24-2.48]$} & .7 \\
\hline \multicolumn{4}{|l|}{ Time since trauma } \\
\hline Less than 6 months & \multirow{2}{*}{\multicolumn{3}{|c|}{$\begin{array}{l}\text { Significance test could not be performed due to small sample-size }(n=5) \\
\text { Significance test could not be performed due to small sample-size }(n=5)\end{array}$}} \\
\hline 6-12 months & & & \\
\hline $1-5$ years & 0.53 & {$[0.15-1.91]$} & .34 \\
\hline $5-10$ years & 0.5 & {$[0.05-4.57]$} & .54 \\
\hline $10-20$ years & 0.73 & {$[0.08-6.78]$} & .79 \\
\hline \multicolumn{4}{|l|}{ Region } \\
\hline Eastern Europe & 0.31 & {$[0-32.26]$} & .62 \\
\hline Africa & \multicolumn{3}{|c|}{ Significance test could not be performed due to small sample-size $(n=7)$} \\
\hline Asia & \multicolumn{3}{|c|}{ Significance test could not be performed due to small sample-size $(n=7)$} \\
\hline Caucasus & \multicolumn{3}{|c|}{ Significance test could not be performed due to small sample-size $(n=8)$} \\
\hline Northern Europe & \multicolumn{3}{|c|}{ Significance test could not be performed due to small sample-size $(n=2)$} \\
\hline
\end{tabular}

Note: CPTSD-class used as reference group for all logistic regression analyses (categorical correlates). *Significant difference. 'More than 20 years' = reference group for 'time since trauma'. 'Middle East' = reference group for 'region'. War as index-trauma has been reported in the current table as it was the most frequently reported index-trauma. No statistically significant differences were identified across class-membership for either index-trauma.

study conducted among treatment-seeking refugees in Switzerland (Hecker et al., 2018). Notable characteristics of the study include that Hecker and colleagues (2018) administered the ITQ as self-report assessment or read it aloud to illiterate participants as in the current study but included the criterion of functional impairment for computation of probable diagnostic status that was unavailable for the current study.
A secondary aim of the current study was to explore relationships between observed class-membership and demographic and trauma-related variables. Although there were no statistically significant differences, age was close to statistical significance at $\mathrm{p}=.05$ with the CPTSD class being slightly older than the PTSD class. Further research is needed to establish whether this trend reaches statistical significance in other samples, as 
previous studies have documented an agerelated increase in prevalence of ICD-11 posttraumatic stress disorders in a German population sample (Maercker, Forstmeier, Wagner, Glaesmer, \& Brähler, 2008).

Differences related to age might explained by older generations' more frequent exposure to war (Burri \& Maercker, 2014). Notably, previously substantiated predictors of PTSD and CPTSD such as trauma exposure (Hecker et al., 2018; Hyland et al., 2017a), female gender (Hyland et al., 2017c), and time since trauma (Vang, BenEzra \& Shevlin, 2019), were unrelated to class membership in the current analysis.

There were no significant differences between observed class membership and type of index trauma. However, previous research among forcibly displaced persons has shown that refugees are exposed to a considerable number of potentially traumatizing events (Elklit, Nørregaard \& Tibor, 1997; Fazel et al., 2005), and recent methodological advances has established that person-oriented approaches to modelling trauma exposure are superior to trauma type and trauma-frequencies in predicting the risk of subsequent mental health issues (O'Donnell et al., 2017). Taken altogether, the limited assessment of trauma exposure in the current study, particularly in childhood, might have precluded the adequate modelling of variability in classes due to exposure to specific trauma types that have been reported in previous research (see for example Frost et al., 2018; Hyland et al., 2017a, c).

There were no statistically significant gender differences across class membership or probable diagnostic status. While some research has suggested that women are more likely to exhibit symptoms consistent with CPTSD in clinical and community samples (Hyland et al., 2017a; Karatzias et al., 2017), other studies like the current have failed to replicate this finding (Maercker et al., 2008). Large scale studies have found that the gender-differentiated risk of posttraumatic symptomatology depends on the nature of the trauma (Ditlevsen \& Elklit, 2010), and combat, war, and terrorism are reported trauma-types with no gender difference in prevalence of PTSD (Tolin \& Foa, 2002). This suggests that the trauma incurred as a result of forcible displacement might constitute a potential threshold of trauma-severity around which gender becomes of marginal importance in predicting variation in posttraumatic symptomatology. Additionally, the high endorsement rates of all symptoms in addition to the high severity of posttraumatic symptomatology in general might constitute a condition under which differences between individuals with different class-membership and diagnostic categories are minimized, as participants with a probable diagnosis of PTSD endorsed between four and five symptom clusters on average, and the participants without a probable diagnosis endorsed between three and four symptom clusters on average (out of a possible six).

Finally, findings from the current study suggested that while assistance from interpreters can be vital to interventions, scale reliability might be compromised when interpreters are used in psychological assessment. However, illiteracy is not uncommon in refugee samples, and concentration difficulties associated with posttraumatic symptomatology (Gil, Caley, Greenberg, Kugelmass \& Lerer, 1990) might pose a frequent problem when completing self-report measures in general. In clinical settings, the influence of working with interpreters in therapy has yielded inconclusive results (Palic \& Elklit, 2011), but according to Carta, Bernal, Hardoy, and 
Haro-Abad (2005) some refugees might feel discomfort due to suspicions of interpreters sharing private information with others, implying a potential for underreporting of some symptoms or experiences. Notably however, assessment of posttraumatic symptomatology among refugees is frequently carried out using verbal provision of questionnaires or using trained interpreters (Grossman et al., 2019; Hecker et al., 2018; Hoffman et al., 2018; Hyland et al., 2018; Murphy et al., 2016; Shrira, Mollov \& Mudahogora, 2019; Valliéres et al., 2018), and it appears that this is the first study accounting for the potential psychometric variation in scale reliability associated with this type of provision of the ITQ to a refugee sample. The ITQscales however performed adequately with reference to recommendations for inter-item correlation set forth by Briggs and Cheek (1986) and issues related to the use of interpreters are secondary compared to the alternative of not performing any systematic assessment of mental health care needs.

Some limitations to the current study are observed when interpreting the findings. The current study was conducted using a self-report assessment among a highly culturally diverse sample of refugees. Results may not generalize to refugee populations in other countries (Denmark has a restrictive selection policy for refugees) or in other settings, as an inclusion criterion for participation in the current study was referral from general practitioner. Assistance of interpreters was needed for most of the participants which affected the reliability of the assessment as evident by the variability in Cronbach's alpha across the different versions. The variability was however confined within an acceptable range. Participants were recruited at the assessment stage rather than directly before treatment, possibly contributing to greater variability in the diagnostic status of the participants. Probable diagnostic status was calculated without the criterion for functional impairment for the ITQ as this was not assessed in the current study, which is also likely to affect the rates of probable PTSD and CPTSD diagnoses. Future research would benefit from the use of translated and validated versions of the ITQ among refugee populations and from assessing functional impairment.

\section{Conclusions}

The current study supports the validity of ICD-11 sibling diagnoses of PTSD and CPTSD among a culturally heterogenous treatment-seeking refugees. The distinction of PTSD and CPTSD is of great importance as CPTSD appears to more accurately describe the symptom profile of this population with clinical implications in terms of intervention-types and -focus. To facilitate further research on the validity of the ICD-11 proposal for PTSD and CPTSD, the ITQ should be translated to African, Middle Eastern and EasternEuropean languages to improve clinical utility and overcome some of the potential issues associated with the use of interpreters.

\section{Clinical implications}

The high number of participants in the CPTSD class raises some concern regarding the sole use of treatment methods for PTSD in this population. Substantial evidence supports short-term trauma-focused interventions (Foa, Keane, Friedman, \& Cohen, 2008), yet research shows only modest reductions in psychopathological symptoms among refugees following treatment (McFarlane \& Kaplan, 2012; Palic \& Elklit, 2011; Slobodin \& de Jong, 2015). 
Most patients do not seem to recover fully from PTSD following treatment (Palic \& Elklit, 2011), and studies that investigate the efficacy of specific interventions for CPTSD have yet to be conducted, although discussion between scholars appears to convene on the general point that more complex symptom presentations require more complex treatment (Buhmann, Mortensen, Nordentoft, Ryberg \& Ekstrøm, 2015; Harlacher et al., 2016). Cloitre et al. (2012) recommended that treatment of CPTSD should include techniques developed and tested for DSO. That is, treatment of CPTSD should include both a traumafocused approach, as well as attending to affective dysregulation, relation difficulties, and a pervasive, negative self-concept. More research is needed to determine the benefits of specific interventions for PTSD and CPTSD, although evidence from a systematic review suggests that CPTSD treatment can indeed build on successful interventions for PTSD (Karatzias et al., 2019).

\section{References}

Akaike, H. (1987). Factor analysis and AIC. In: Selected Papers of Hirotugu Akaike (pp. 371-386). New York: Springer.

American Psychiatric Association. (2000). Diagnostic and Statistical Manual of Mental Disorders (4th ed., text rev.). Washington, DC: Author.

American Psychiatric Association. (2013). Diagnostic and Statistical Manual of Mental Disorders (5th ed.). Washington, DC: Author.

Ben-Ezra, M., Karatzias, T., Hyland, P., Brewin, C.R., Cloitre, M., Bisson, J.I., Roberts, N.P., Lueger-Schuster, B., \& Shevlin, M. (2018). Posttraumatic stress disorder (PTSD) and complex PTSD (CPTSD) as per ICD-11 proposals: A population study in Israel. Depression and Anxiety, 35 (3), 264-274. doi: 10.1002/ da. 22723

Bogic, M., Njoku, A., \& Priebe, S. (2015). Longterm mental health of war-refugees: a systematic literature review. BMC International Health and Human Rights, 15(1), 29. doi: 10.1186/s12914015-0064-9
Brewin, C.R., Cloitre, M., Hyland, P., Shevlin, M., Maercker, A., Bryant, R.A., ... Reed, G.M. (2017). A review of current evidence regarding the ICD-11 proposals for diagnosing PTSD and complex PTSD. Clinical Psychology Review, 58, 1-15. doi: 10.1016/j.cpr.2017.09.001

Briggs, S. R., \& Cheek, J. M. (1986). The role of factor analysis in the development and evaluation of personality scales. Fournal of Personality, 54(1), 106-148.

Buhmann, C., Mortensen, E. L., Nordentoft, M., Ryberg, J., \& Ekstrøm, M. (2015). Follow-up study of the treatment outcomes at a psychiatric trauma clinic for refugees. Torture, 25(1), 1-16. doi: https://doi.org/10.7146/torture.v25i1.109505

Burri A., \& Maercker A. (2014). Differences in prevalence rates of PTSD in various European countries explained by war exposure, other trauma and cultural value orientation. BMC Research Notes, 7, 407. doi:10.1186/1756-0500-7-407

Carta, M.G., Bernal, M., Hardoy, M.C., \& HaroAbad, J.M. (2005). Migration and mental health in Europe (the state of the mental health in Europe working group: appendix 1). Clinical Practice and Epidemiology in Mental Health, 1, 13-29. doi: 10.1186/1745-0179-1-13

Cloitre, M., Courtois, C. A., Ford, J. D., Green, B. L., Alexander, P., Briere, J., ... Van der Hart, O. (2012). The ISTSS expert consensus treatment guidelines for complex PTSD in adults. Retrieved from https://www.istss.org/ ISTSS_Main/media/Documents/ISTSS-ExpertConcesnsus-Guidelines-for-Complex-PTSDUpdated-060315.pdf

Cloitre, M., Garvert, D. W., Brewin, C. R., Bryant, R. A., \& Maercker, A. (2013). Evidence for proposed ICD-11 PTSD and complex PTSD: A latent profile analysis. European fournal of Psychotraumatology, 4, 20706. doi: 10.3402/ejpt. v4i0.20706

Cloitre, M., Garvert, D.W., Weiss, B., Carlson, E.B., \& Bryant, R.A. (2014). Distinguishing PTSD, Complex PTSD, and Borderline Personality Disorder: A latent class analysis. European fournal of Psychotraumatology, 5, 25097.

Cloitre, M., Roberts, N., Bisson, J.I., \& Brewin, C.R., (2013). Self-Report Community Version 1.0. Translated by Elklit, A. (2015). Unpublished manuscript.

Cloitre, M., Shevlin, M., Brewin, C.R., Bisson, J.I., Roberts, N.P., Maercker, A., Karatzias, T., \& Hyland, P. (2018). The International Trauma Questionnaire: Development of a self-report measure of ICD-11 PTSD and Complex PTSD. Acta Psychiatrica Scandinavia, 138(6), 536-546. 
doi: 10.1111/acps.12956

Competence Centre for Transcultural Psychiatry (2015). Tidlig intervention kan være nøglen til behandling af svær patientgruppe. [Early intervention might be key to treating a challenging patient-group] Retrieved from: https:/www.psykiatri-regionh.dk/presse-og-nyt/ pressemeddelelser-og-nyheder/Nyheder-ogpressemeddelelser/Sider/Tidlig-interventionkan-være-nøglen-til-behandling-af-sværpatientgruppe.aspx.

DIGNITY. (2019). Fakta om tortur | DIGNITY Dansk Institut Mod Tortur. [Facts about torture | DIGNITY - Danish Institute Against Torture] Retrieved from: https:/dignity.dk/dignitysarbejde/fakta-om-tortur/

Ditlevsen, D. N., \& Elklit, A. (2010). The combined effect of gender and age on post-traumatic stress disorder: do men and women show differences in the lifespan distribution of the disorder? Annals of General Psychiatry, 9(1), 32. doi: 10.1186/1744859X-9-32

Elklit, A., Nørregaard, J., Tibor, B. (1997). Traumatisering hos unge bosniske flygtninge i Danmark. [Traumatization among young Bosnian refugees in Denmark] Psykologisk Pedagogisk Rådgivning, 34, 3-18.

Fazel, M., Wheeler, J., \& Danesh, J. (2005). Prevalence of serious mental disorder in 7000 refugees resettled in western countries: a systematic review. The Lancet, 365(9467), 1309-1314. doi: 10.1016/ S0140-6736(05)61027-6

Foa, E. B., Keane, T. M., Friedman, M. J., \& Cohen, J. (2008). Effective treatments for PTSD: Practice guidelines from the international society for traumatic stress studies (2nd ed.). New York, NY: Guilford.

Frost, R., Hyland, P., McCarthy, A., Halpin, R., Shevlin, M., \& Murphy, J. (2019). The complexity of trauma exposure and response: Profiling PTSD and CPTSD among a refugee sample. Psychological Trauma: Theory, Research, Practice, and Policy, 11(2), 165. doi: 10.1037/ tra0000408.

Geiser, C. (2010). Data analysis with Mplus. New York: Guilford Press.

Gil, T., Calev, A., Greenberg, D., Kugelmass, S., \& Lerer, B. (1990). Cognitive functioning in post》 traumatic stress disorder. Fournal of Traumatic Stress, 3(1), 29-45. doi: https://doi.org/10.1002/ jts. 2490030104

Grossman, E. S., Hoffman, Y. S., Shrira, A., Kedar, M., Ben-Ezra, M., Dinnayi, M., \& Zivotofsky, A. Z. (2019). Preliminary evidence linking complexPTSD to insomnia in a sample of Yazidi genocide survivors. Psychiatry Research, 271, 161-166. doi: 10.1016/j.psychres.2018.11.044

Harlacher, U., Polatin, P., Buhmann, C. B., Nordentoft, M., Ekstroem, M., Lohmann, J. C., \& Mortensen, E. L. (2016) Comment and response to the commentary. Torture fournal, 26(1), 5-5.

Hecker, T., Huber, S., Maier, T., \& Maercker, A. (2018). Differential Associations Among PTSD and Complex PTSD Symptoms and Traumatic Experiences and Postmigration Difficulties in a Culturally Diverse Refugee Sample. Fournal of Traumatic Stress, 31(6), 795-804. doi: 10.1002/ jts. 22342 .

Hoffman, Y. S., Grossman, E. S., Shrira, A., Kedar, M., Ben冈Ezra, M., Dinnayi, M., ... \& Zivotofsky, A. Z. (2018). Complex PTSD and its correlates amongst female Yazidi victims of sexual slavery living in post冈ISIS camps. World Psychiatry, 17(1), 112. doi: $10.1002 /$ jts. 22342 .

Hyland, P., Ceannt, R., Daccache, F., Daher, R. A., Sleiman, J., Gilmore, B., ... \& Vallières, F. (2018). Are posttraumatic stress disorder (PTSD) and complex-PTSD distinguishable within a treatment-seeking sample of Syrian refugees living in Lebanon? Global Mental Health, 5. doi: doi: $10.1017 / \mathrm{gmh} .2018 .2$

Hyland, P., Murphy, J., Shevlin, M., Vallières, F., McElroy, E., Elklit, A., ... \& Cloitre, M. (2017a). Variation in post-traumatic response: the role of trauma type in predicting ICD-11 PTSD and CPTSD symptoms. Social Psychiatry and Psychiatric Epidemiology, 52(6), 727-736. doi: 10.1007/s00127-017-1350-8.

Hyland, P., Shevlin, M., Brewin, C.R., Cloitre, M., Downes, A.J., Jumbe, S., ... Roberts, N.P. (2017b). Validation of post-traumatic stress disorder (PTSD) and complex PTSD using the International Trauma Questionnaire. Acta Psychiatrica Scandinavica, 136, 313-322. doi: 10.1111/acps. 12771

Hyland, P., Shevlin, M., Elklit, A., Murphy, J., Vallières, F., Garvert, D. W., \& Cloitre, M. (2017c). An assessment of the construct validity of the ICD-11 proposal for complex posttraumatic stress disorder. Psychological Trauma: Theory, Research, Practice, and Policy, 9(1), 1. doi: 10.1037/tra0000114.

Hyland, P., Shevlin, M., Fyvie, C., \& Karatzias, T. (2018). Posttraumatic Stress Disorder and Complex Posttraumatic Stress Disorder in DSM-5 and ICD-11: Clinical and Behavioral Correlates. Fournal of Traumatic Stress, 31, 174180. doi:10.1002/jts.22272.

Karatzias, T., Cloitre, M., Maercker, A., Kazlauskas, E., Shevlin, M., Hyland, P., ... Brewin, C. R. 
(2017). PTSD and Complex PTSD: ICD-11 updates on concept and measurement in the UK, USA, Germany and Lithuania. European fournal of Psychotraumatology, 8, 1418103. doi.org/10.108 0/20008198.2017.1418103

Karatzias, T., Murphy, P., Cloitre, M., Bisson, J., Roberts, N., Shevlin, M., ... \& Mason-Roberts, S. (2019). Psychological interventions for ICD-11 complex PTSD symptoms: systematic review and meta-analysis. Psychological Medicine, 1-15. doi: 10.1017/S0033291719000436.

Karatzias T., Shevlin M., Fyvie C., Hyland P., Efthymiadou E., Wilson D., ... Cloitre M. (2016). An initial psychometric assessment of an ICD-11 based measure of PTSD and complex PTSD (ICD-TQ): Evidence of construct validity. Fournal of Anxiety Disorders, 44, 73-79. doi: 10.1016/j.janxdis.2016.10.009.

Knefel, M. \& Lueger-Schuster, B. (2013). An evaluation of ICD-11 PTSD and complex PTSD criteria in a sample of adult survivors of childhood institutional abuse. European fournal of Psychotraumatology, 4, 22608.

Lo, Y., Mendell, N. R., \& Rubin, D. B. (2001). Testing the number of components in a normal mixture. Biometrika, 88(3), 767-778.

Maercker, A., Brewin, C. R., Bryant, R. A., Cloitre, M., Reed, G. M., Van Ommeren, M. ... Saxena, S. (2013a). Proposals for mental disorders specifically associated with stress in the ICD-11. Lancet, 381, 1683-1685. doi: 10.1016/S01406736(12)62191-6

Maercker, A., Brewin, C. R., Cloitre, M., Van Ommeren, M., Jones, L. M., Humayan, A. ... Reed, G. M. (2013b). Diagnosis and classification of disorders specifically associated with stress: proposals for ICD-11. World Psychiatry, 12 (3).

Maercker A., Forstmeier S., Wagner B., Glaesmer H., \& Brähler E. (2008). Posttraumatische Belastungsstörungen in Deutschland. Ergebnisse einer gesamtdeutschen epidemiologischen Untersuchung [Post-traumatic stress disorder in Germany. Results of a nationwide epidemiological study]. Nervenarzt, 79, 577-586. doi: doi.org/10.1007/s00115-008-2467-5

McElroy, E., Shevlin, M., Murphy, S., Roberts, B., Makhashvili, N., Javakhishvili, J., ... \& Hyland, P. (2019). ICD-11 PTSD and complex PTSD: structural validation using network analysis. World Psychiatry: Official Fournal of the World Psychiatric Association (WPA)18(2), 236-237. doi: 10.1002/ wps. 20638.

McFarlane, C.A., \& Kaplan, I. (2012). Evidencebased psychological interventions for adult survivors of torture and trauma: A 30-year review. Transcultural Psychiatry, 49 (3-4), 539-567. doi: $10.1177 / 1363461512447608$

McLachlan, G.J., \& Peel, D. (2000). Finite Mixture Models. New York: Wiley

Muthén, L.K. \& Muthén, B.O. (2018). Mplus User's Guide (version 8.1). Los Angeles, CA: Muthén \& Muthén.

Murphy S., Elklit A., Dokkedahl S., \& Shevlin M. (2016). Testing the validity of the proposed ICD11 PTSD and complex PTSD criteria using a sample from Northern Uganda. European fournal of Psychotraumatology, 7(1), 32678. doi: 10.3402/ ejpt.v7.32678.

Murphy, J., Houston, J. E., \& Shevlin, M. (2007). Principles and applications of latent class analysis in psychological research. The Irish fournal of Psychology, 28(1-2), 87-96.

Nickerson, A., Cloitre, M., Bryant, R. A., Schnyder, U., Morina, N., \& Schick, M. (2016). The factor structure of complex posttraumatic stress disorder in traumatized refugees. European Fournal of Psychotraumatology, 7(1), 33253. doi: 10.3402/ejpt.v7.33253.

Nylund, K.L., Asparouhov, T., \& Muthén, B.O. (2007). Deciding on the number of classes in latent class analysis and growth mixture modeling: A Monte Carlo simulation study. Structural Equation Modeling, 14, 535-569.

O’Donnell, M. L., Schaefer, I., Varker, T., Kartal, D., Forbes, D., Bryant, R. A., ... \& Felmingham, K. (2017). A systematic review of person-centered approaches to investigating patterns of trauma exposure. Clinical Psychology Review, 57, 208-225. doi: 10.1016/j.cpr.2017.08.009.

Palic, S. (2013). Measurement and Documentation of Complex PTSD in Treatment Seeking

Traumatized Refugees. University of Southern Denmark: Doctoral dissertation. doi: 10.1016/j. psychres.2016.10.062

Palic, S., \& Elklit, A. (2011). Psychosocial treatment of posttraumatic stress disorder in adult refugees: a systematic review of prospective treatment outcome studies and a critique. Fournal of Affective Disorders, 131 (1-3), 8-23. doi: 10.1016/j. psychres.2016.10.062.

Palic, S., Zerach, G., Shevlin, M., Zeligman, Z., Elklit, A., Solomon, Z. (2016). Evidence of complex posttraumatic stress disorder (CPTSD) across populations with prolonged trauma of varying interpersonal intensity and ages of exposure. Psychiatry Research, 246, 692-699.

Ramaswamy, V., DeSarbo, W. S., Reibstein, D. J., \& Robinson, W. T. (1993). An empirical pooling approach for estimating marketing mix 
elasticities with PIMS data. Marketing Science, 12(1), 103-124.

Schwarz, G.E. (1978). Estimating the dimension of a model. The Annals of Statistics, 6(2), 461-464.

Sclove, S. L. (1987). Application of model-selection criteria to some problems in multivariate analysis. Psychometrika, 52(3), 333-343.

Shevlin, M., Hyland, P., Vallières, F., Bisson, J., Makhashvili, N., Javakhishvili, J., ... \& Roberts, B. (2018). A comparison of DSM $₫ 5$ and ICD $\otimes 11$ PTSD prevalence, comorbidity and disability: an analysis of the Ukrainian Internally Displaced Person's Mental Health Survey. Acta Psychiatrica Scandinavica, 137(2), 138-147. doi: 10.1111/ acps. 12840 .

Shrira, A., Mollov, B., \& Mudahogora, C. (2019). Complex PTSD and intergenerational transmission of distress and resilience among Tutsi genocide survivors and their offspring: A preliminary report. Psychiatry Research, 271, 121123. doi: 10.1016/j.psychres.2018.11.040.

Silove, D., Rees, S., Mohsin, M., Tam, N., Kareth, M., \& Tay, A. K. (2018). Differentiating ICD11 complex post-traumatic stress disorder from other common mental disorders based on levels of exposure to childhood adversities, the traumas of persecution and postmigration living difficulties among refugees from West Papua. British fournal of Psychiatry Open, 4(5), 361-367. doi: 10.1192/bjo.2018.49.

Slobodin, O., \& de Jong, J.T.V.M. (2015). Mental health interventions for traumatized asylum seekers and refugees: What do we know about their efficacy? International fournal of Social Psychiatry, 61 (1) 17-26. doi: 10.1177/0020764014535752

Tam, S. Y., Houlihan, S., \& Melendez-Torres, G. J. (2017). A systematic review of longitudinal risk and protective factors and correlates for posttraumatic stress and its natural history in forcibly displaced children. Trauma, Violence, E Abuse, 18(4), 377-395. doi: $10.1177 / 1524838015622437$.

Tay, A. K., Rees, S., Chen, J., Kareth, M., \& Silove, D. (2015). The structure of post-traumatic stress disorder and complex post-traumatic stress disorder amongst West Papuan refugees. BMC Psychiatry, 15, 111. doi: 10.1186/s12888-0150480-3.

Tay, A. K., Rees, S., Tam, N., Kareth, M., \& Silove, D. (2018). Defining a combined constellation of complicated bereavement and PTSD and the psychosocial correlates associated with the pattern amongst refugees from West Papua. Psychological Medicine, 1-9. doi: 10.1017/
S0033291718002027.

Tolin, D. F., \& Foa, E. B. (2008). Sex differences in trauma and posttraumatic stress disorder: A quantitative review of 25 years of research. Psychological Trauma: Theory, Research, Practice, and Policy, $S$ (1), 37-85.

Turrini, G., Purgato, M., Ballette, F., Nosè, M., Ostuzzi, G., \& Barbui, C. (2017). Common mental disorders in asylum seekers and refugees: umbrella review of prevalence and intervention studies. International fournal of Mental Health Systems, 11(1), 51. doi: 10.1186/ s13033-017-0156-0.

UNHCR. (2018). Global trends. Forced displacement in 2017. United Nations.

US Dept. of Health and Human Service. (2019). Survivors of Torture Program. Retrieved from https://www.acf.hhs.gov/orr/programs/survivorsof-torture

Vallières, F., Ceannt, R., Daccache, F., Abou Daher, R., Sleiman, J., Gilmore, B., ... \& Hyland, P. (2018). ICD 11 PTSD and complex PTSD amongst Syrian refugees in Lebanon: the factor structure and the clinical utility of the International Trauma Questionnaire. Acta Psychiatrica Scandinavica, 138(6), 547-557. doi: 10.1111/acps. 12973

Yuan, K. H., \& Bentler, P. M. (2000). Three likelihood冈based methods for mean and covariance structure analysis with nonnormal missing data. Sociological Methodology, 30(1), 165-200. 